PNL-SA-21492

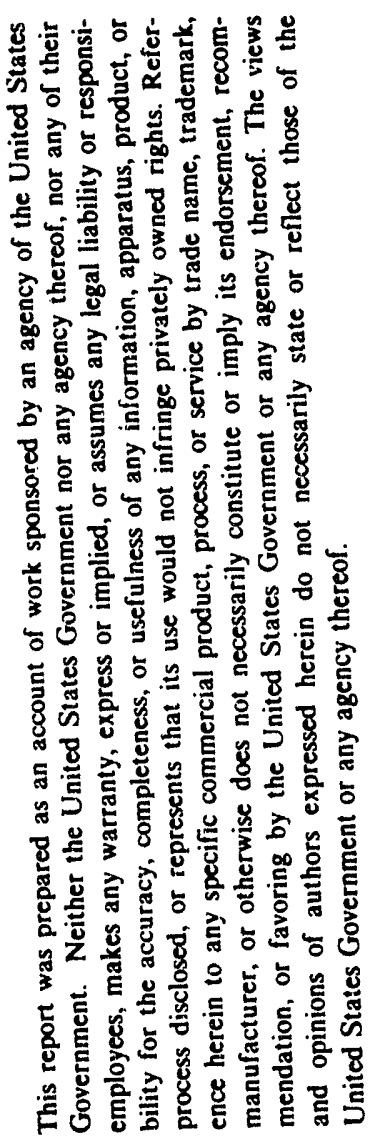

SPATIAL AND TEMPORAL VARIABILITY OF PRECIPITATION AND CHEMISTZYY: CASE STUDIES FROM THE FRONTAL BOUNDARY STUDY

HECEIVED

FEB 181993

OSTI

M. T. Dana

January 1993

Presented at the

American Meteorological Society 73rd Annual Meeting

January 17-22, 1993

Anaheim, California

Work supported by

the U.S. Department of Energy

under Contract DE-ACO6-76RLO 1830

Pacific Northwest Laboratory

Richland, Washington 99352

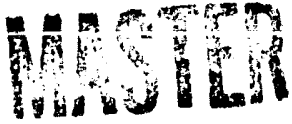




\title{
SPATLAL AND TEMPORAL VARIABILITY OF PRECIPITATION AND CHEMISTRY: CASE STUDIES FROM THE FRONTAL BOUNDARY STUDY
}

\author{
M. Terry Dana \\ Pacific Northwest Laboratory \\ Richland, Washingt on
}

\section{INTRODUCTION}

Regional and larger-scale models of pollutant transport and deposition generally, by practical necessity, must be limited in output of precipitation rate and chemical composition to values 1 or selected time intervals representing areas on the order of $10^{4} \mathrm{~km}^{2}$. Naturally, it is of some r.nncern that these values be reasonably reprcsen-

of natural variations both in time and space. $\therefore$ is question may be approached through field studies involving detailed spatial (using a network of samplers on the model grid scale) and temporal (using sequential sampling) measurements. This paper presents an initial analysis, using simple statistical concepts, of data bases from such a field study, the Frontal Boundary Study (FBS).

\section{EXPERIMENTAL}

The precipitation chemistry network for FBS was designed to provide ground support for aircraft measurements of atmospheric chemistry in the vicinity of cyclonic storm fronts. The network, shown in Figure 1, consists of 37 sites with a nominal site-spacing of $16 \mathrm{~km}$ and a higher-density central area. Most of the sites were located on vegetated farm land or park areas, and all met standard criteria for location of regional or background sampling sites (Dana and Easter 1987).

The precipitation sampling device located at all sites was the computer-controlled automated rain sampler (CCARS), a battery-powered combination recording rain gauge and sequential chemistry sampler. The CCARS is capable of providing the time history of rainfall in $0.25-\mathrm{mm}(0.01-\mathrm{in}$.) increments, and up to 9 sequential samples for chemical analysis. The CCARS were programmed to sample on a volume basis, for $2.5 \mathrm{~mm}$ (0.1 in.)

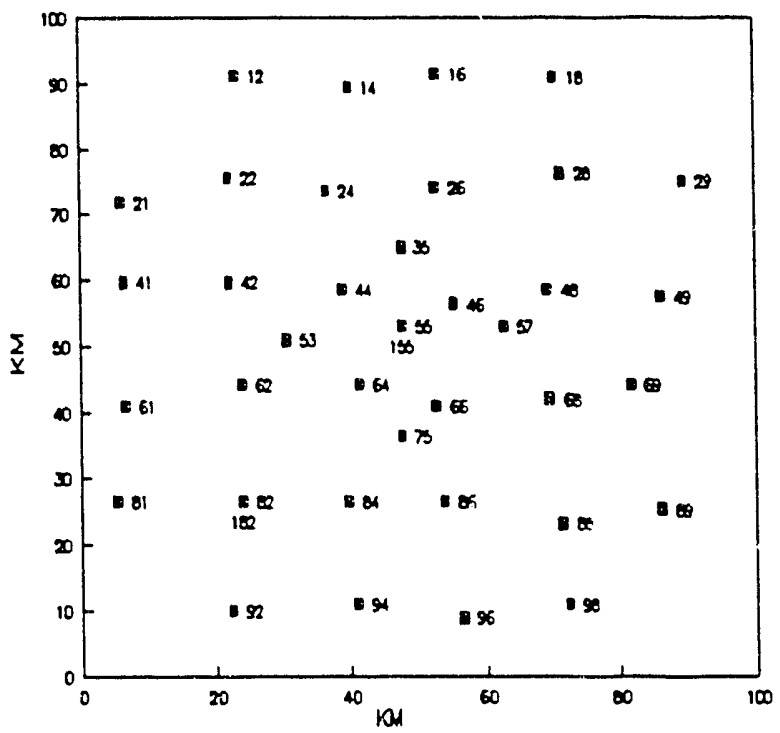

Figure 1. The FBS precipitation chemistry network. The center of the network is about $80 \mathrm{~km}$ northnortheast of Columbus International Airport.

per stage on the first eight stages. The final stage can contain up to $50 \mathrm{~mm}$ (2 in.) of rainfall. Detail on the operation and capabilities of the CCARS may be found in Tomich and Dana (1990). Major ion analyses for rain water samples were performed at the Pacific Northwest Laboratory precipitation chemistry laboratory in Richland, Washington, following quality procedures establisbed for the MAP3S precipitation chemistry network (Dana and Easter 1987).

During the operational period of FBS, precipitation of significant spatial and temporal extent for full measurement operations was experienced on four occasions. Table 1 is a brief summary of the meteorological situations, timing, and extent of operations. 
TABLE 1

\section{SUMMARY OF FBS EVENTS AND NETWORK MEASUREMENTS}

\begin{tabular}{|c|c|c|c|c|c|}
\hline \multirow{2}{*}{$\begin{array}{l}\text { Date of } \\
\text { Rainfall } \\
(1989)\end{array}$} & \multirow[b]{2}{*}{$\begin{array}{l}\text { Event } \\
\text { Number }\end{array}$} & \multirow[b]{2}{*}{$\begin{array}{l}\text { Synoptic } \\
\text { Situation }\end{array}$} & \multicolumn{3}{|c|}{ Network } \\
\hline & & & $\begin{array}{l}\text { Sites } \\
\text { in Service }\end{array}$ & $\begin{array}{l}\text { Sequential } \\
\text { Samples }^{(a)}\end{array}$ & $\begin{array}{l}\text { Rainfall, } \\
\mathrm{mm}^{(b)}\end{array}$ \\
\hline Oct. $10-11$ & 11 & Warm sector & 23 & 5 & 10 \\
\hline Oct. $16-17$ & 17 & $\begin{array}{l}\text { Cold front/Tropical } \\
\text { Depression }\end{array}$ & 29 & $1-9^{(c)}$ & $0-32^{(c)}$ \\
\hline Oct. 31 & 01 & Cold front & 35 & 4 & 5 \\
\hline Nov. 7 & 08 & Warm Front & 12 & 4 & 8 \\
\hline \multicolumn{6}{|c|}{$\begin{array}{l}\text { (a) Typical number per site. } \\
\text { (b) Aproximate average for network. } \\
\text { (c) Widely variable. }\end{array}$} \\
\hline
\end{tabular}

\section{DATA ANALYSIS}

The data record for a CCARS site consists of the times of completion of each $0.25 \mathrm{~mm}$ of rainfall and entries documenting the time of rainfall start and no-rainfall periods. Once chemical analysis of the stage volumes was completed, the chemical data were added to each time record. Statistics characterizing the spatial distributions of rainfall rates and amounts and chemical concentrations were calculated from hourly and also from event (precipitation-weighted) results. In addition, the fractional differences between bourly and event values for site pairs and the separation distances were computed. The fractional differences are given by

$$
\begin{gathered}
C_{f}=\left|C_{j}-C_{k}\right| / C_{m} \\
J_{f}=\left|J_{j}-J_{k}\right| / J_{m}
\end{gathered}
$$

where $C_{j}$ and $C_{k}$ are concentrations, $J_{j}$ and $J_{k}$ may be either rainfall amounts or rates, at sites $j$ and $k$; and $C_{m}$ and $J_{m}$ are the mean network averages for the time period. The site separation distances, $D_{j k}$ are given by

$$
D_{j k}=\left[\left(x_{j}-x_{k}\right)^{2}+\left(y_{j}-y_{k}\right)^{2}\right]^{1 / 2}
$$

where $x_{j}, x_{k}, y_{j}$, and $j_{k} a$ " the Cartesian spatial coordinates. All concentrations are presented in $\mu \mathrm{M}$, rainfall in $\mathrm{mm}$, rainfall rate in $\mathrm{mm} / \mathrm{hr}$, and distances in $\mathrm{km}$.

The chemical concentrations of inorganic ionic species are often negatively correlated with precipitation rate or amount (Dana and Easter 1987, Hales and Dana 1979). As a consequence, one must consider whether rainfall variations bave an effect on spatial or temporal variations in chemistry. If the concentration-rainfall relationship is estimated by the general power-law regression formula

$$
C=A J^{B}
$$

then substitution into Equation (1) provides an expression estimating the "precipitation variations" component of the fractional differences in chemistry between sitie pairs:

$$
C_{r}=A\left|J_{j}^{B}-J_{k}^{B}\right| / C_{m}
$$

The difference $C_{p}=C_{f}-C_{r}$ then represents an estimate of the precipitation-variations-corrected fractional difference. 


\section{TEMPORALLY-AVERAGED \\ VARIATIONS: EVENT DATA}

The event concentrations and total event rainfall data are useful for an initial analysis of spatial variations because 1) the data bases are generally more robust statistically than sub-event data sets, 2) any sub-event temporal variations are averaged, 3) the relationships between chemical concentrations and precipitation amount are robust and comparable to event data from other sources, and 4) gross differences among the events--which may be reflected in temporal variations--can be more easily defined.

The distributions of the fractional differences $C_{f}$ and $J_{f}$ are broad, and though regressions of these on inter-site distance sometimes show a positive correlation, these trends are far from prominent, and there is considerable variance at all distances. To reduce some of the variance and clarify the distance relationships, the $\mathrm{C}_{\mathrm{f}}$-distance data were smoothed by assigning $C_{f}$ values to equally-populated distance bins and $C_{f}$ averages for

-, in were computed. Plots of sulfate binw. $\mathrm{C}_{\mathrm{f}}$ are shown in Figure 2. (Event $17 \mathrm{~F}$ is the cold-front-related portion of the October 17 network data.) Two events exhibit values for $C_{f}$ that are on the order of laboratory analysis error $(10 \%)$, and only slight distance dependence. The other events show stronger distance trends and overall higher $C_{f}$.

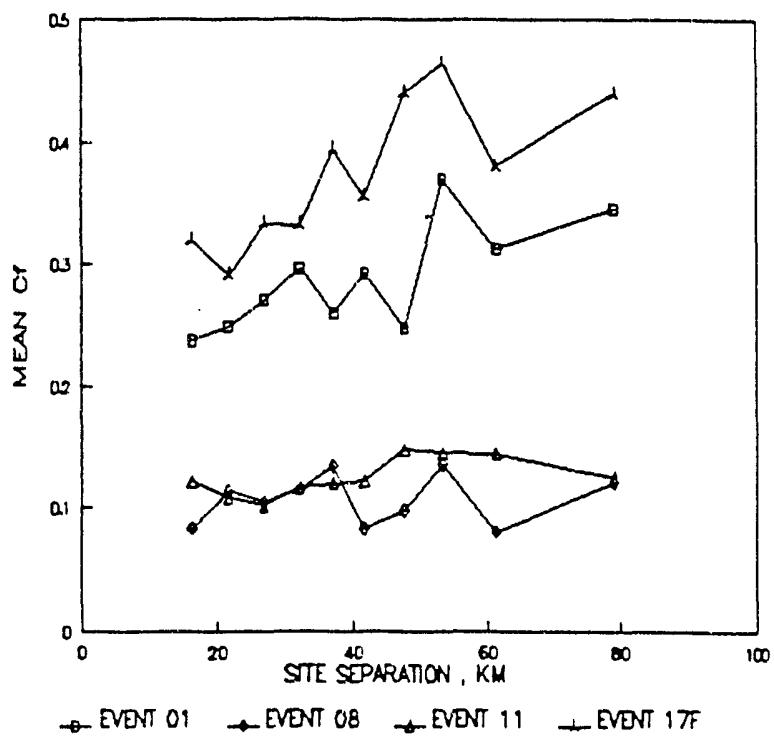

Figure 2. Event mean distance-bin fractional differences for sulfate.
Figure 3 shows the results, for the same cases, of correcting for the estimated precipitation amount variations (i.e., $C_{p}$ ). The effect is to bring the events more closely in agreement, and to reduce the distance effect to some degree. In the case of event 17F, the rainfall amount effect is so large that a negative estimate is produced. Any predicted variation below $10 \%$ should not be considered real. istic, in view of normal measurement variability.

The mean $C_{f}$ and $C_{p}$ for the major species are summarized in Figures 4 and 5. The considerable variations for all species in event 17 can be accounted for by rainfall amount variations, and the events show similar patterns among the species if the rainfall effect is removed. Many of the mean $C_{f}$ values approach the level of normal experimental error. Among the species showing the least variance and distance trend is sulfate, the species which one might expect to vary considerably in space, either because its original sourcc is $\mathrm{SO}_{2}$ plumes, or because it is subject to production via both liquidphase and gas-phase reactions. Apparently, at least for these events in this region, the source term for sulfate is spatially uniform, and/or the processes leading to its formation and removal were spatially uniform.

A further analysis of the distance trends for the various species and events involves assessing the statistical significance of the distance

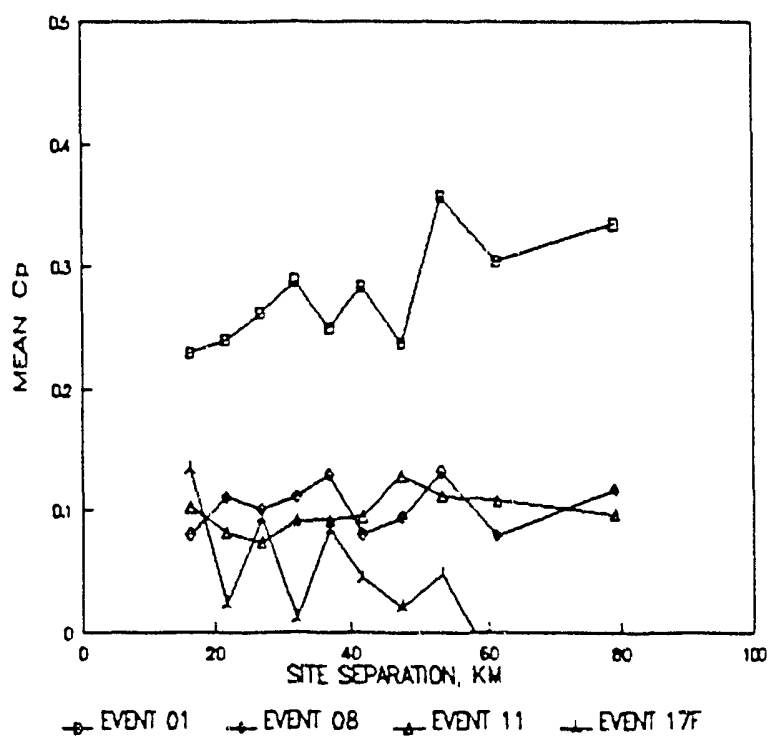

Figure 3. Event mean distance-bin precipitationvariation-corrected fractional differences for sulfate. 


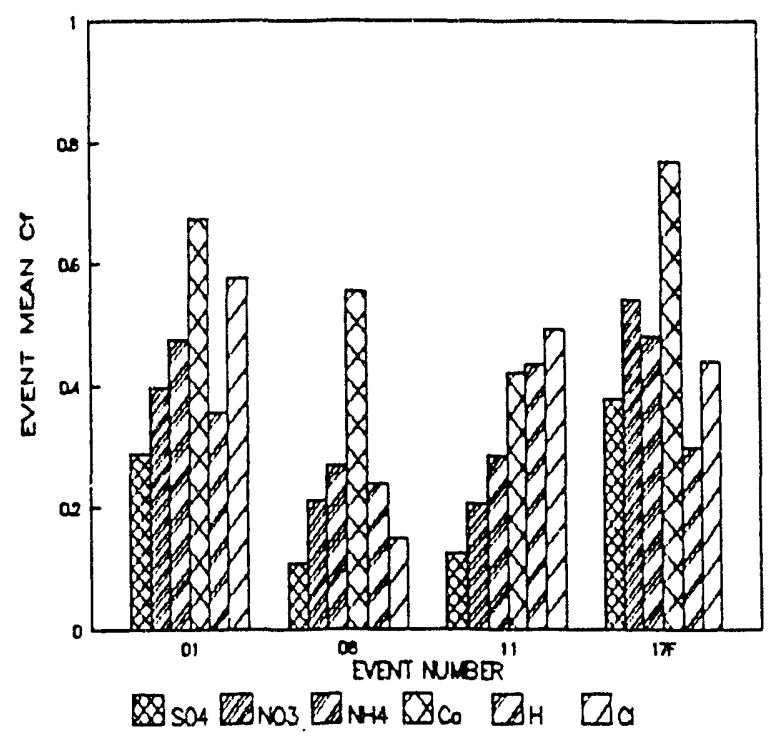

Figure 4. Event mean fractional differences for major chemical species.

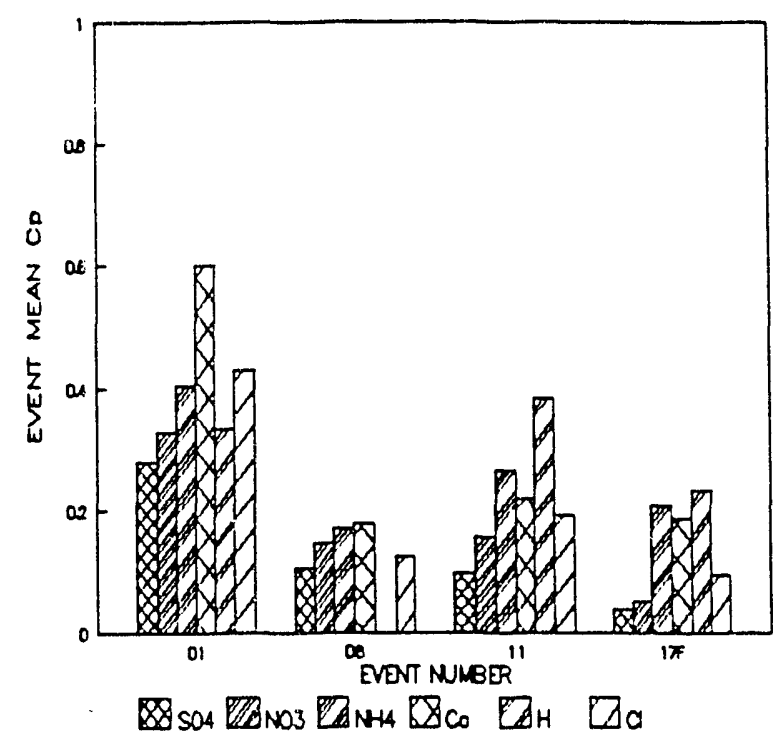

Figure 5. Event mean precipitation-variationcorrected fractional differences for major chemical species.

trends for: 1) the observed variance, 2) the calculated rainfall-effect variance, and 3) the difference between the two. Of the 44 robust species/event combinations, 16 or $36 \%$ show no significant trends for any variable (Student-t test). The second most prevalent set (11 or 25\%) has significant trends for $\mathrm{C}_{f}$ and $\mathrm{C}_{\mathrm{r}}$ [Equation (5)], but not for the difference. Thus for this set, the rainfall effect is the dominant distance trend. Ten, or $23 \%$, of the cases have a significant distance trend remaining after the correction. The various cases were about equally proportioned among the species, as one would expect from the strong correlations among them. Among the events, event 17 and the nonindependent sub-events $17 \mathrm{~F}$ and $17 \mathrm{~T}$ dominated the rainfalleffect-dominant cases. Two events (08 and 11$)$ bad no rainfall effect and only two significant difference cases.

\section{SPATLALLY-AVERAGED TEMPORAL VARIATIONS: SEQUENTIAL DATA}

To assess the spatial patterns in temporal trends, it is necessary to assign a time scale applicable for the area of interest, and to construct time averages over suitably sized time intervals. In view of the rainfall amount resolution of the chemistry and the variability of rainfall rate among and between events, a time interval of one hour was chosen for use on all the events to allow comparability among the events.

The most obvious choice for the time scale is time of day, or "real time" $\left(T_{d}\right)$. However, the rainfall most often does not begin simultaneously within the grid-scale area, so one should examine variations in terms of a "rainfall" time scale, or the time since the rain begins at each given site $\left(\mathrm{T}_{\mathrm{T}}\right)$. A third time scale that could be applied is developed in terms of the motion of the precipitation system, specifically the progression of a front across the area $\left(T_{f}\right)$.

The same analyses were performed on the sequential data as were done for the event data above, except that time averaging was done for hourly time periods. Rainfall data reflect hourly rainfall rate, rather than total rainfall for the hours. Table 2 lists means and coefficients of variation (COV) for sulfate concentration, bourly rainfall rate, the merns of the inter-site normalized fractional differences, and the fraction of the variations estimated to be due to rainfall rate variations. These results are for the rainfall time scale $T_{r}$; the statistics are more robust and the time trends are generally smoother than for the other time scales.

As with the event data, there is considErabit scatter in the hourly $\mathrm{C}_{f}$-inter-site distance relationships. Generally, during the early $T_{d}$ hours of the events, an increase in variance with distance is indicatec. These trends are missing or are more obscure when the $T_{r}$ scale is used. The rainfallcorrected variances, $C_{p}$, generally follow the patterns exhibited with the event data, 
TABLE 2

SPATIALLY-AVERAGED TEMPORAL VARIATIONS FOR TIME SCALE TR: SPECIES SULFATE (S) AND RAIN RATE (J). ONLY HOURS WITH N > 5 INCLUDED

\begin{tabular}{|c|c|c|c|c|c|c|c|c|c|}
\hline Hour & $\mathrm{N}$ & $\begin{array}{c}S \\
\text { Mean, } \\
\mu \mathrm{m}\end{array}$ & $\stackrel{\mathrm{S}}{\mathrm{COV}}$ & $\begin{array}{c}\mathrm{J} \\
\text { Mean, } \\
\mathrm{mm} / \mathrm{hr}\end{array}$ & $\begin{array}{c}\mathrm{J} \\
\mathrm{COV}\end{array}$ & $\begin{array}{l}\text { Sf } \\
N\end{array}$ & $\begin{array}{c}\text { Sf } \\
\text { Mean }\end{array}$ & $\begin{array}{c}\text { Jf } \\
\text { Mean }\end{array}$ & $\underset{\%}{\mathrm{Sr} / \mathrm{Sf}}$ \\
\hline \multicolumn{10}{|c|}{ Event 01} \\
\hline 1 & 28 & 39 & 0.308 & 2.53 & 0.213 & 378 & 0.353 & 0.245 & 6 \\
\hline 2 & 26 & 18 & 0.275 & 2.20 & 0.248 & 325 & 0.297 & 0.262 & 12 \\
\hline 3 & 20 & 14 & 0.228 & 1.66 & 0.427 & 190 & 0.266 & 0.498 & 20 \\
\hline 4 & 9 & 13 & 0.220 & 0.49 & 0.372 & 36 & 0.262 & 0.441 & 24 \\
\hline \multicolumn{10}{|c|}{ Event 08} \\
\hline 1 & 11 & 24 & 0.228 & 2.20 & 0.613 & 55 & 0.269 & 0.605 & 55 \\
\hline 2 & 10 & 21 & 0.168 & 1.03 & 0.755 & 45 & 0.200 & 0.806 & 6 \\
\hline 3 & 11 & 20 & 0.252 & 0.79 & 0.781 & 55 & 0.296 & 0.886 & 23 \\
\hline 4 & 9 & 21 & 0.112 & 2.48 & 0.474 & 36 & 0.129 & 0.549 & 43 \\
\hline 5 & 9 & 21 & 0.200 & 1.59 & 0.595 & 36 & 0.231 & 0.69 .5 & 30 \\
\hline 6 & 8 & 22 & 0.119 & 0.60 & 0.417 & 28 & 0.143 & 0.443 & 73 \\
\hline 7 & 6 & 31 & 0.217 & 0.26 & 0.091 & 15 & 0.254 & 0.108 & 77 \\
\hline \multicolumn{10}{|c|}{ Event 11} \\
\hline 1 & 14 & 35 & 0.175 & 1.92 & 0.650 & 91 & 0.200 & 0.595 & 44 \\
\hline 2 & 13 & 32 & 0.156 & 2.44 & 0.340 & 78 & 0.183 & 0.394 & 32 \\
\hline 3 & 13 & 34 & 0.218 & 1.64 & 0.376 & 78 & 0.257 & 0.441 & 6 \\
\hline 4 & 7 & 37 & 0.190 & 2.10 & 0.370 & 2.1 & 0.214 & 0.442 & 26 \\
\hline 5 & 7 & 39 & 0.327 & 1.75 & 0.834 & 21 & 0.379 & 0.977 & 60 \\
\hline \multicolumn{10}{|c|}{ Event $17 \mathrm{~F}$} \\
\hline 1 & 10 & 42 & 0.341 & 8.16 & 0.752 & 45 & 0.376 & 0.893 & 74 \\
\hline 2 & 13 & 37 & 0.412 & 2.11 & 1.035 & 78 & 0.483 & 1.086 & 72 \\
\hline 3 & 8 & 35 & 0.281 & 1.26 & 0.626 & 28 & 0.326 & 0.759 & 51 \\
\hline 4 & 6 & 34 & 0.239 & 2.12 & 1.361 & 15 & 0.293 & 1.415 & 63 \\
\hline
\end{tabular}


although the rainfall effect is considerably more obscure in most cases due to reduced robustness of the concentration-rainfall rate relationships.

\section{CONCLUSIONS}

Spatial coefficients of variation for event concentrations of chemical species range from about 0.1 to about 0.8 , with sulfate one of the least variable, while rainfall amount and rate variability are up to three times larger. Correcting approximately for the rainfall variations results in a reduction of the chemical variability to a level approaching experimental uncertainty for three of the four events. There appear to be "baseline" spatial variabilities for events of about $20 \%$ or less. Inter-site differences in concentrations generally correlate positively with inter-site distances, but rainfall corrections remove the significance for a number of the event/species cases. Reasons for the differences in the variability characteristics of the ants may be ascertained through detailed mete-

$\therefore$ al studies, storm simulation studies, and seadiysus of FBS aircraft chemistry measurements.

\section{ACKNOWLEDGMENT}

This work was supported by the U.S. Department of Energy under Contract DE-AC0676RLO 1830. Pacific Northwest Laboratory is operated for the U.S. Department of Energy by Battelle Memorial Institute.

\section{REFERENCES}

Dana, M. Terry and R. C. Easter, 1987: Statistical summary and analyses of event precipitation chemistry from the MAP3S network, 1976-1983. Atmos. Environ. 21(1), 113-128.

Hales, J. M and M. Terry Dana, 1979: Precipitation scavenging of urban pollutants by convective storm systems. J. Appl. Meteor..18, 294-316.

Tomich, S. D. and M. Terry Dana, 1990: Computer-controlled automated rain sampler (CCARS) for rainfall measurements and sequential sampling. J. Atmos. Ocean. Tech.,7(4), 541-549. 

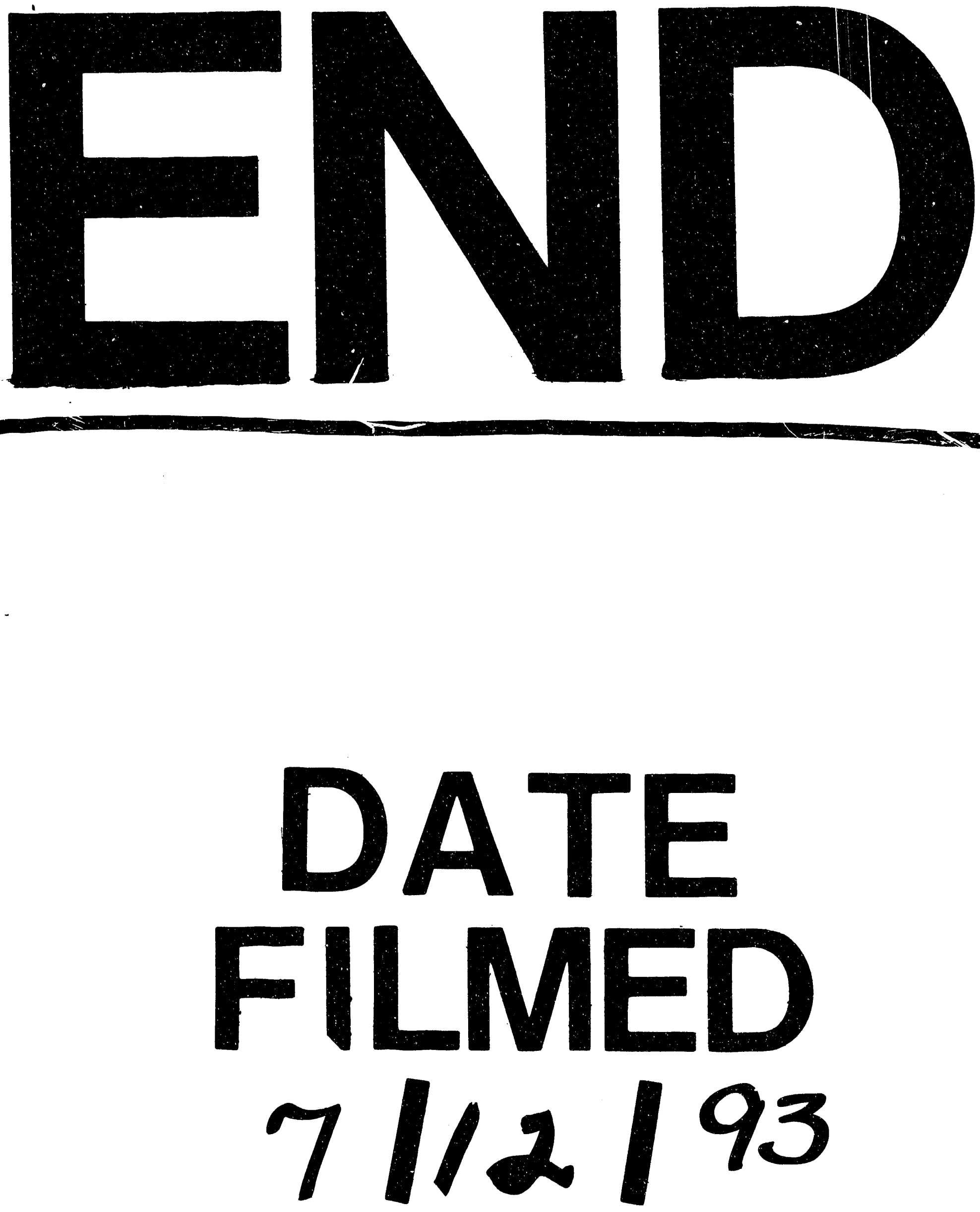

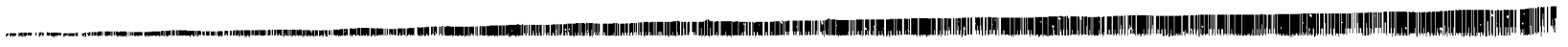


